Vol. 6, No. 1, Februari 2018

Efektifitas Media Film dengan Leaflet dalam Peningkatan Pengetahuan Ibu Rumah Tangga tentang DBD di Desa Pekalongan Kabupaten Pati

Dobby Raka Sandi Susetya, Ervi Rachma Dewi

Menggali Kefektifan Peran Ibu dengan Anak Usia Pra Sekolah selama Berada di Rutan Kudus Aliani Nailil Izzah, Sri Hindriyastuti

Perbedaan Kadar BOD Limbah Cair Sebelum dan Setelah melewati Biofilter Tanaman Cattail (Typha angustifolia) Pujo Prasetyo, David Laksamana Caesar

Gambaran Kepatuhan Ibu dalam Pelaksanaan Imunisasi DPT/Hb Lengkap di Puskesmas Punggelan 2 Kabupaten Banjarnegara Lia Aria Ratmawati, Rosiyani Hermawati

Hubungan Riwayat Kontak Penderita dengan Kejadian Tuberkulosis Paru Anak Usia 1-14 Tahun di Balai Kesehatan Masyarakat Pati Risna Endah Budiati, Noor Khoirina

Hubungan Dukungan Keluarga dengan Pemberian ASI Eksklusif pada Bayi di Desa Jambean Kidul Kecamatan Margorejo Nanik Royaningsih, Sri Wahyuningsih

Jumlah Kehamilan dan Kematian Ibu Berdasarkan Letak Wilayah Ketinggian di Kabupaten Pekalongan Rokhani, Indri Astuti Purwanti 


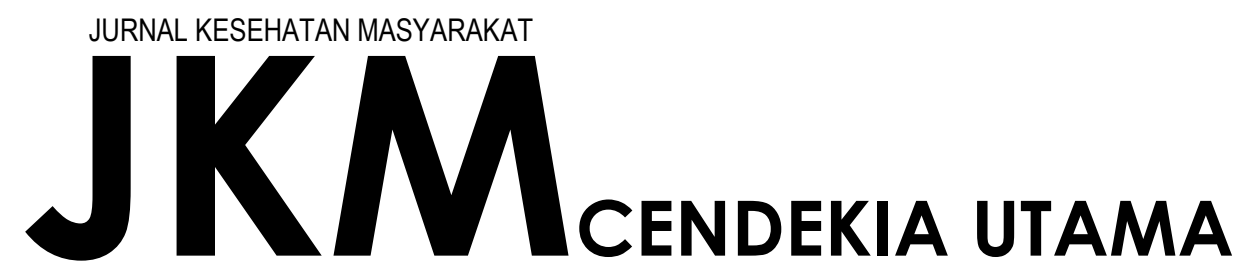


Vol. 6 No. 1

P-ISSN 2338-6347

Februari, 2018

E-ISSN 2580-992X

\section{$\mathbf{J} \mathbf{M}_{\text {cendekia utama }}$}

\section{Editor in Chief}

Eko Prasetyo, S.KM., M.Kes. STIKES Cendekia Utama Kudus, Indonesia

\section{Editorial Board}

Sri Wahyuningsih, S.KM., M.Gizi., STIKES Cendekia Utama Kudus, Indonesia Risna Endah Budiati, S.KM., M.Kes., (Epid), STIKES Cendekia Utama Kudus, Indonesia

Ervi Rachma Dewi, S.KM., M.Kes., STIKES Cendekia Utama Kudus, Indonesia David Laksamana Caesar, S.KM., M.Kes., STIKES Cendekia Utama Kudus, Indonesia

\section{Reviewer}

Sigit Ari Saputro, S.KM., M.Kes., Universitas Airlangga, Surabaya, Indonesia dr. Mahalul Azam, M.Kes., Universitas Negeri Semarang, Indonesia

Eti Rimawati, S.KM., M.Kes., Universitas Dian Nuswantoro, Semarang, Indonesia Didik Sumanto, S.KM., M.Kes. (Epid), Universitas Muhammadiyah Semarang, Indonesia

\section{English Language Editor}

Arina Hafadhotul Husna, M.Pd., STIKES Cendekia Utama Kudus, Indonesia

\section{IT Support}

Susilo Restu Wahyuno, S.Kom, STIKES Cendekia Utama Kudus, Indonesia

JKM (Jurnal Kesehatan Masyarakat) Cendekia Utama merupakan jurnal ilmiah dalam bidang kesehatan masyarakat yang diterbitkan oleh Program

Studi S1 IImu Kesehatan Masyarakat STIKES Cendekia Utama Kudus secara berkala dua kali dalam satu tahun 


\section{KATA PENGANTAR}

Salam MIRACLE,

Puji syukur selalu senantiasa kita panjatkan kehadirat Allah SWT yang telah melimpahkan Rahmah Hidayah dan Ilmu-Nya, sehingga JKM (Jurnal Kesehatan Masyarakat) Cendekia Utama Kudus Vol. 6, No. 1 dapat kembali terbit pada bulan Februari 2018 ini. Pada kesempatan yang baik ini kami menyampaikan ucapan terima kasih dan apresiasi yang setinggi-tingginya kepada bapak ibu mitra bestari, para peneliti, tim redaksi, dan semua pihak yang telah mendukung atas terbitnya JKM Cendekia Utama Vol. 6, No. 1 ini.

JKM Cendekia Utama merupakan jurnal ilmiah di bidang kesehatan masyarakat yang diterbitkan secara berkala 2 (dua) kali dalam setahun oleh Program Studi S1 Ilmu Kesehatan Masyarakat STIKES Cendekia Utama Kudus. JKM Cendekia Utama mempublikasikan informasi ilmiah hasil penelitian dengan kajian: Epidemiologi, Kesehatan Lingkungan, Keselamatan dan Kesehatan Kerja (K3), Promosi Kesehatan, Biostatistik dan Kependudukan, Administrasi Kebijakan Kesehatan (AKK), Manajemen Kesehatan, Gizi Masyarakat, Kesehatan Ibu dan Anak (KIA), Kesehatan Reproduksi, dan kajian-kajian pengembangan ilmu di bidang kesehatan masyarakat.

JKM Cendekia Utama kembali mengundang berbagai ilmuan dari berbagai lembaga pendidikan tinggi maupun peneliti untuk memberikan sumbangan ilmiahnya dalam bentuk artikel ilmiah dari hasil penelitian, laporan/studi kasus, kajian/tinjauan pustaka di bidang kesehatan masyarakat dalam rangka mengatasi permasalahan kesehatan masyarakat yang semakin kompleks.

Redaksi sangat mengharapkan masukan-masukan dari para pembaca dan professional bidang kesehatan masyarakat untuk peningkatan kualitas jurnal dan berharap semoga artikel-artikelyang termuat dalam JKM Cendekia Utama bermanfaat dalam pengembangan ilmu di bidang kesehatan masyarakat.

\section{Pimpinan Redaksi}

Eko Prasetyo, S.KM., M.Kes. 


\section{DAFTAR ISI}

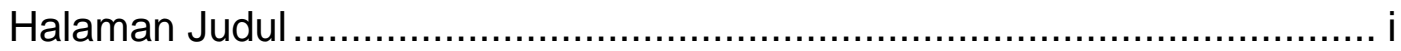

Susunan Dewan Redaksi..................................................................

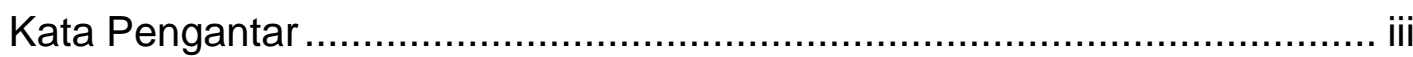

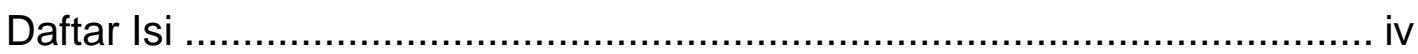

Efektifitas Media Film dengan Leaflet dalam Peningkatan Pengetahuan Ibu Rumah Tangga tentang DBD di Desa Pekalongan Kabupaten Pati Dobby Raka Sandi Susetya, Ervi Rachma Dewi........................................ 1

Menggali Kefektifan Peran Ibu dengan Anak Usia Pra Sekolah selama Berada di Rutan Kudus

Aliani Nailil Izzah, Sri Hindriyastuti........................................................ 16

Perbedaan Kadar BOD Limbah Cair Sebelum dan Setelah melewati Biofilter Tanaman Cattail (Typha angustifolia)

Pujo Prasetyo, David Laksamana Caesar

Gambaran Kepatuhan Ibu dalam Pelaksanaan Imunisasi DPT/Hb Lengkap di Puskesmas Punggelan 2 Kabupaten Banjarnegara

Hubungan Riwayat Kontak Penderita dengan Kejadian Tuberkulosis Paru Anak Usia 1-14 Tahun di Balai Kesehatan Masyarakat Pati Risna Endah Budiati, Noor Khoirina.

Hubungan Dukungan Keluarga dengan Pemberian ASI Eksklusif pada Bayi di Desa Jambean Kidul Kecamatan Margorejo

Jumlah Kehamilan dan Kematian Ibu Berdasarkan Letak Wilayah Ketinggian di Kabupaten Pekalongan

Rokhani, Indri Astuti Purwanti 62

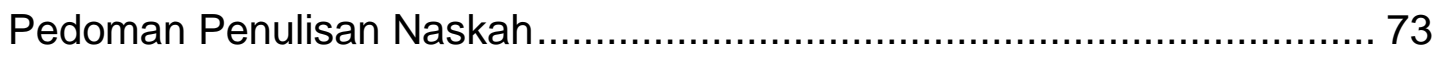

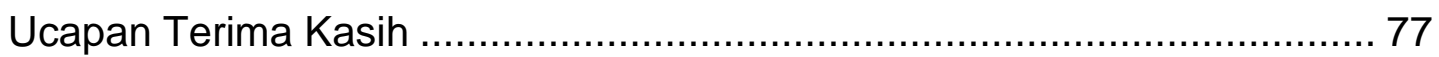




\title{
PERBEDAAN KADAR BOD LIMBAH CAIR SEBELUM DAN SETELAH MELEWATI BIOFILTER TANAMAN CATTAIL (Typha angustifolia)
}

\author{
Pujo Prasetyo ${ }^{1}$, David Laksamana Caesar ${ }^{2}$ \\ 1,2 Program Studi IImu Kesehatan Masyarakat \\ STIKES Cendekia Utama Kudus \\ Jl. Lingkar Raya Kudus-Pati Km. 5 Jepang, Mejobo, Kudus Telp (0291) 4248655 \\ pudjo.prasetyo94@gmail.com, davidlaksamanacaesar@gmail.com
}

\begin{abstract}
ABSTRAK
Limbah cair yang dihasilkan dari industri tapioka masih mengandung padatan tersuspensi dan terlarut yang dapat mencemari perairan salah satunya adalah tingginya kadar BOD, oleh karena itu harus diturunkan kadarnya sebelum dibuang ke perairan. Salah satu cara yang dapat dilakukan adalah dengan cara biofilter. Biofilter yang digunakan adalah menggunakan tanaman Cattail (Thypa angustifolia) dengan sistem Constructed wetland. Penelitian ini bertujuan untuk mengetahui perbedaan kadar BOD limbah cair sebelum dan setelah melewati biofilter tanaman cattail (Typha angustifolia) dengan sistem constructed wetland. Jenis penelitian ini adalah penelitian eksperimen semu (quasi eksperiment). Dalam penelitian ini digunakan pendekatan pre-test post-test design. Sampel penelitian adalah limbah cair industri tapioka di Desa Ngemplakkidul Kecamatan Margoyoso Kabupaten Pati. Kemudian dilakukan perlakuan dengan menggunakan biofilter tanaman Cattail (Typha angustifolia) usia tanam 10 hari. Analisa data yang digunakan adalah Uji Paired T Test. Nilai rata-rata sebelum perlakuan sebesar $613,99 \mathrm{mg} / \mathrm{L}$, Nilai rata-rata setelah perlakuan sebesar 367,89 mg/L. Sedangkan rata-rata prosentase penurunan kadar BOD adalah $41,54 \%$. Hasil analisis Uji Normalitas data sebelum perlakuan sebesar 0,530 dan nilai setelah perlakuan sebesar 0,530 . Nilai tersebut lebih besar dari taraf signifikansi $0,005>0,530$ maka data terdistribusi normal, maka dapat dilakukan Uji Paired T Test. Berdasarkan hasil Uji Paired T Test diperoleh nilai T sebesar 215,159 dan nilai signifikansi sebesar 0,000 artinya ada perbedaan kadar BOD sebelum dan setelah melewati biofilter tanaman Cattail (Typha angustifolia). Berdasarkan analisa dan pembahasan diatas terdapat perbedaan kadar BOD antara sebelum dan setelah melewati biofilter tanaman Cattail.
\end{abstract}

Kata Kunci : BOD, Biofilter, Tanaman Catail, Limbah Cair Tapioka

\section{ABSTRACT}

Liquid waste from tapioca industy still contains suspended and dissolved solids that can contaminate the waters one of which is high BOD content, so it have to lowered before being discharged to water. One of way that can be done with biofilter. The biofilter used is cattail plant (Typha angustifolia) with a constructed wetland system. This research aims to determine the difference of BOD content 
of liquid waste before and after through cattail plant biofilter (Typha angustifolia) with construted wetland system. This type of research is a quasi-experimental research used pre-test approach post-test design. The research sample was a liquid waste of tapioca industry in the Village of Ngemplakkidul Margoyoso subdistrict Pati. Then performed a way by using cattail plant biofilter (Typha angustifolia) age of 10 days planting. Data analysis used is Paired T Test. The average value before the treatment amounted to $613,99 \mathrm{mg} / \mathrm{L}$, the average value after treatment is equal to $367,89 \mathrm{mg} / \mathrm{L}$. While the average percentage decrease in $B O D$ content is $41,54 \%$. The result of normality data test before treatment is 0,530 and value after treatment equal to 0,530. Value is greater than the level of significance 0,005 >0,530 then the data is normally distributed, then can use Paired T Test. Based on Paired T Test results obtained T value of 215,159 and a significance value of 0,000 , means there are differences in contens of $B O D$ before and after through biofilter cattail plant (Typha angustifolia). Based on the analysis and discussion there is a difference BOD content between before and after through cattail plant biofilter.

Keywords : BOD, Biofilter, Cattail, Tapioca liquid waste. 


\section{PENDAHULUAN}

Pertumbuhan industri dewasa ini telah banyak memberikan sumbangan bagi perekonomian Indonesia melalui produk barang atau jasa yang dihasilkan, namun disisi lain pertumbuhan industri telah menimbulkan masalah lingkungan yang cukup serius. Buangan air limbah industri mengakibatkan timbulnya pencemaran air sungai yang dapat merugikan masyarakat yang tinggal disepanjang aliran sungai, seperti berkurangnya hasil produk pertanian, menurunnya hasil tambak, maupun berkurangnya pemanfaatan air sungai oleh penduduk.[1]

Industri tapioka merupakan usaha yang di dirikan dalam rangka pengembangan kegiatan di bidang pangan yang mempunyai dampak positif dan negatif bagi lingkungan. Dampak positif berupa pemenuhan kebutuhan masyarakat akan sumber pangan sedangkan dampak negatif berupa limbah buangan yang menimbulkan masalah pencemaran sehingga merusak lingkungan. Pencemaran lingkungan tersebut berupa hasil pembuangan limbah cair.

Limbah cair yang mengandung padatan tersuspensi maupun terlarut, mengalami perubahan fisik, kimia, dan hayati yang akan menghasilkan zat beracun atau menciptakan media untuk tumbuhnya kuman. Salah satu cara untuk mengetahui seberapa jauh beban pencemaran pada air limbah adalah dengan mengukur BOD (Biological Oxygen Demand) [2] sesuai dengan Peraturan Menteri Lingkungan Hidup Republik Indonesia No 5 Tahun 2014 tentang Baku Mutu Air Limbah.[3]

BOD (Biological Oxygen Demand) atau kebutuhan oksigen biologis adalah jumlah oksigen yang dibutuhkan oleh mikroorganisme di dalam air lingkungan untuk memecah (mendegradasi) bahan buangan organik yang ada di dalam air lingkungan tersebut.[4]

Pengolahan limbah yang cukup murah dan aman adalah biofilter menggunakan tanaman air, contohnya cattail (Typha angustifolia). Cattail (Typha angustifolia) adalah jenis tumbuhan yang bersifat colonial. Tumbuhan ini juga mempunyai akar rizom serta berbentuk panjang dan 
ramping. Tumbuhan cattail memiliki rhyzosfera merupakan sistem perakaran yang banyak dapat menyerap zat organik di badan air. [2]

Hasil penelitian Mika (2013), pemanfaatan tanaman cattail (Typha angustifolia) menggunakan sistem constructed wetland dapat menurunkan limbah industri tahu sebesar BOD $640 \mathrm{mg} / \mathrm{L}$ (30,3\%) dari kadar limbah awal dimana BOD sebesar $1232 \mathrm{mg} / \mathrm{L}$. Sedangkan penelitian Nurul dan Wahyu (2010), menunjukkan bahwa dengan menggunakan tanaman Cattail (Typha angustifolia) dalam sistem lahan basah buatan pengolahan air limbah domestik dapat penyisihan kandungan pencemar dalam air limbah dengan efisiensi penyisihan BOD 47,4\% - 91,6\%. Penelitian ini dilakukan untuk mengetahui perbedaan kadar BOD limbah cair sebelum dan setelah melewati biofilter tanaman cattail (Typha angustifolia).

\section{METODE PENELITIAN}

Jenis penelitian ini adalah penelitian eksperimen semu (quasi experiment). Dalam penelitian ini digunakan pendekatan pre-test post-test design. Populasi dalam penelitian ini adalah limbah cair tapioka dan sampel penelitian ini adalah limbah cair industri tapioka di Desa Ngemplakkidul Kecamatan Margoyoso Kabupaten Pati. Kemudian dilakukan perlakuan dengan menggunakan biofilter tanaman Cattail (Typha angustifolia) usia tanam 10 hari di Desa Cabak RT 04/08 Tlogowungu, Pati. Dilakukan analisa di UPT Laboratorium Kabupaten Kudus. Penelitian ini dilaksanakan menggunakan media toples plastik ukuran $10 \mathrm{~L}$ dengan media krikil, pasir, tanah dan tanaman cattail. Kemudian limbah dialirkan secara vertikal ke dalam media. Uji analisis yang digunakan adalah Uji Paired T Test.

\section{HASIL DAN PEMBAHASAN \\ Hasil \\ Kadar BOD Limbah Cair Tapioka di Desa Ngemplak Kidul Kecamatan Margoyoso Kabupaten Pati}


Tabel 1

Hasil Analisis Kadar BOD Limbah Cair Tapioka

\begin{tabular}{ccccc}
\hline No & Nama Sampel & $\begin{array}{c}\text { Sebelum } \\
\text { Perlakuan }\end{array}$ & $\begin{array}{c}\text { Setelah } \\
\text { Perlakuan }\end{array}$ & $\begin{array}{c}\text { Prosentase } \\
\text { Penurunan Kadar } \\
\text { BOD }\end{array}$ \\
\hline 1 & Sampel media A & 707,48 & 459,74 & $35,02 \%$ \\
\hline 2 & Sampel media B & 703,93 & 456,02 & $35,22 \%$ \\
\hline 3 & Sampel media C & 706,86 & 458,63 & $35,12 \%$ \\
\hline 4 & Sampel media D & 488,76 & 245,17 & $49,84 \%$ \\
\hline 5 & Sampel media E & 462,96 & 219,92 & $52,50 \%$ \\
\hline
\end{tabular}

Sumber : Data Primer, 2017

Berdasarkan tabel 1 dapat diketahui sebanyak lima (5) sampel percobaan, setiap masing-masing media menggunakan sampel limbah tapioka yang sama. Masing-masing media dengan hasil yang berbedabeda. Hasil analisis nilai rata-rata sebelum perlakuan sebesar 613,99 $\mathrm{mg} / \mathrm{L}$, nilai minimum sebesar $462,96 \mathrm{mg} / \mathrm{L}$ dan nilai maksimum sebesar $707,48 \mathrm{mg} / \mathrm{L}$. Hasil analisis nilai rata-rata setelah perlakuan sebesar $367,89 \mathrm{mg} / \mathrm{L}$, nilai minimum sebesar 219,92 $\mathrm{mg} / \mathrm{L}$ dan nilai maksimum $459,74 \mathrm{mg} / \mathrm{L}$. Maka terdapat perbedaan antara sebelum perlakuan dan setelah dilakuakan perlakuan.

Hasil analisis selisih sebelum dan setelah dilakukan perlakuan pada sampel media A sebesar 247,74 mg/L, sampel media B 247,91 mg/L, sampel media C 248,23 mg/L, sampel media D 243,59 mg/L dan sampel media E sebesar $243,04 \mathrm{mg} / \mathrm{L}$. Hal ini menunjukkan ada beda antara sebelum dan setelah dilakukan perlakuan. Penurunan kadar BOD pada penelitian ini sebelum dan setelah melewati biofilter tanaman Cattail (Typha angustifolia) pada sampel media A sebesar 35,22 \%, sampel media B 35,22 \%, sampel media C 35,12\%, sampel media D 49,84\%, sampel media E 52,50\%. Persentase rata-rata penurunan kadar BOD sebesar $41,54 \%$.

Hasil analisis Uji Normalitas data sebelum perlakuan sebesar 0,530 dan nilai setelah perlakuan sebesar 0,530 . Nilai tersebut lebih besar dari 
taraf signifikansi $0,005>0,530$, maka data terdistribusi normal, dan dapat dilakukan Uji Paired T Test.

Berdasarkan hasil Uji Paired $T$ Test diperoleh nilai signifikansi sebesar 0,000, artinya terdapat perbedaan antara kadar BOD limbah cair tapioka sebelum perlakuan dan setelah perlakuan. Serta diperoleh nilai $T$ sebesar 215,159. Nilai tersebut menunjukkan bahwa sebelum perlakuan nilai kadar BOD lebih besar dari pada setelah perlakuan. Hal ini menunjukkan bahwa biofilter efektif dalam menurunkan kadar BOD limbah cair tapioka dengan nilai rata-rata penurunan $215,159 \mathrm{mg} / \mathrm{L}$.

\section{Pembahasan}

Kadar BOD Limbah Cair Tapioka di Desa Ngemplak kidul Kecamatan Margoyoso Kabupaten Pati Kondisi awal kadar limbah cair sebelum dilakukan pengujian memiliki kandungan BOD yang sangat tinggi dan melampaui batas standar baku mutu limbah yang di tetapkan oleh pemerintah. Menurut Peraturan Menteri Negara Lingkungan Hidup Republik Indonesia Nomor 05 Tahun 2014 tentang Baku Mutu Air Limbah Industri Tapioka yang belum dikelola dengan kadar BOD maksimal sebesar $150 \mathrm{mg} / \mathrm{L}$. [3]

Nilai analisis sebelum dilakukan perlakauan pada kandungan awal limbah tapioka pada sampel media A sebesar $707,48 \mathrm{mg} / \mathrm{L}$, sampel media B 703,93 mg/L, sampel media C 706,86 mg/L, sampel media D 488,76 $\mathrm{mg} / \mathrm{L}$ dan media $\mathrm{E}$ sebesar $462,96 \mathrm{mg} / \mathrm{L}$. Setiap media terdapat perbedaan kadar BOD masing-masing, pada sampel media $D$ dan $E$ diperoleh kadar yang berbeda dengan sampel media A,B,C dikarenakan saat melakukan penuangan pada botol sampel atau winkler dengan cara bergantian, semakin banyak jumlah oksigen yang masuk ke dalam botol. Sehingga hal ini menyebabkan terjadinya proses aerasi dan kadar BOD menjadi rendah.

Analisis limbah tapioka setelah melewati biofilter tanaman Cattail (Typha angustifolia) pada sampel media A sebesar 459,74 mg/L, sampel 
media B 456,02 mg/L, sampel media C 458,63 mg/L, sampel media D $245,17 \mathrm{mg} / \mathrm{L}$, dan sampel media E sebesar 219,92 mg/L. Semua media terdapat perbedaan kadar BOD pada masing- masing media.

Berdasarkan hasil penelitian yang dilakukan terdapat selisih kadar BOD sebelum dan setelah melewati biofilter tanaman Cattail (Typha angustifolia) dengan nilai kadar BOD sebelum melewati biofilter tanaman Cattail (Typha angustifolia) pada sampel media A sebesar 707,48 mg/L, sampel media B 703,93 mg/L, sampel media C 706,86 mg/L, sampel media $D$ 488,76 mg/L dan media E sebesar $462,96 \mathrm{mg} / \mathrm{L}$. Sedangkan nilai kadar BOD setelah melewati biofilter tanaman Cattail (Typha angustifolia) pada sampel media A sebesar 459,74 mg/L, sampel media B 456,02 $\mathrm{mg} / \mathrm{L}$, sampel media C 458,63 mg/L, sampel media D 245,17 mg/L, dan sampel media E sebesar 219,92 mg/L. Nilai selisih kadar BOD sebelum dan setelah melewati biofilter tanaman Cattail (Typha angustifolia) pada sampel media A sebesar $247,74 \mathrm{mg} / \mathrm{L}$, sampel media B $247,91 \mathrm{mg} / \mathrm{L}$, sampel media C 248,23 mg/L, sampel media D 243,59 mg/L dan sampel media E sebesar $243,04 \mathrm{mg} / \mathrm{L}$. Setiap masing-masing sampel media terdapat perbedaan kadar BOD pada limbah tapioka.

Berdasarkan hasil analisa data menggunakan SPSS dengan Uji Paired T Test diketahui nilai signifikansi sebesar 0,000, yang artinya ada perbedaan kadar BOD sebelum dan setelah melewati biofilter tanaman Cattail (Typha angustifolia). Penurunan kadar BOD pada penelitian ini sebelum dan setelah melewati biofilter tanaman Cattail (Typha angustifolia) pada sampel media A sebesar $35,22 \%$, sampel media B $35,22 \%$, sampel media C 35,12 \%, sampel media D 49,84\%, sampel media E 52,50 \%. Prosentase rata-rata penurunan kadar BOD sebesar $41,54 \%$.

Berdasarkan penelitian Susilo (2015), penurunan kadar BOD limbah tapioka menggunakan Metode Rotating Biological Contactor dengan variasi waktu dan kondisi awal limbah sebesar $3852 \mathrm{mg} / \mathrm{L}$. Setelah dilakukan perlakuan dengan variasi waktu 12 jam kadar BOD menjadi 
3047 mg/L, 32 jam 675,2 mg/L, 48 jam 150,1 mg/L.[5] Berdasarkan penelitian Hariono (2015), penurunan konsentrasi limbah cair industri tapioka menggunakan Metode Rotating Biological Contactor (RBC) pada kecepatan putaran cakram 50 dan $100 \mathrm{rpm}$ dengan kondisi awal limbah cair tapioka sebesar $1217 \mathrm{mg} / \mathrm{L}$. Pada kecepatan putaran cakram $50 \mathrm{rpm}$ kadar BOD menjadi 127 mg.L, sedangkan kecepatan putaran cakram 100 rpm sebesar 96,67 mg/L.[6]

Terdapat perbedaan kadar BOD sebelum dan setelah perlakuan karena kondisinya berbeda sebelum melewati biofilter tanaman Cattail (Typha angustifolia) dan setelah melewati biofilter. Limbah cair tapioka setelah melewati biofilter tanaman Cattail, padatan - padatan atau endapan - endapan didalam limbah akan tersaring oleh akar tanaman Cattail, tanah, pasir maupun krikil yang akan menjadi oksidasi dan kadar BOD akan menjadi turun. Hal ini juga sama berdasarkan laporan kajian FAO (Food and agriculture organization, 2007) tentang sistem pengolahan limbah, bahwa tanaman cattail (Typha angustifolia) berpotensi mengolah limbah buangan industri. Tanaman cattail (Typha angustifolia) mampu mereduksi kandungan logam (Bareen \& Khilji dikutip dalam jurnal Shinta 2014).[7]

\section{SIMPULAN DAN SARAN}

\section{Simpulan}

Berdasarkan hasil penelitian tentang perbedaan kadar BOD limbah cair tapioka menggunakan biofilter tanaman Cattail (Typha angustifilia) di Desa Ngemplak Kidul Kecamatan Margoyoso Kabupaten Pati dapat disimpulkan bahwa kondisi awal limbah cair tapioka sebelum melewati biofilter tanaman Cattail (Typha angustifolia) dengan nilai rata-rata sebesar $613,99 \mathrm{mg} / \mathrm{L}$. Kondisi limbah cair tapioka setelah melewati biofilter tanaman Cattail (Typha angustifolia) dengan nilai rata-rata sebesar 367,89 $\mathrm{mg} / \mathrm{L}$. Terdapat selisih kadar BOD sebelum melewati biofilter tanaman Cattail (Typha angustifolia) dengan nilai prosentase rata-rata penurunan 
kadar BOD sebesar 41,54\%. Hasil uji Paired T Test nilai nilai signifikansi sebesar 0,000, artinya terdapat perbedaan kadar BOD sebelum dan setelah melewati biofilter tanaman Catail dan nilai T sebesar 215,159.

\section{Saran}

\section{Bagi Peneliti Selanjutnya}

Mengingat keterbatasan penelitian dalam melakukan penelitian sehingga kurang mampu menghasilkan penelitian yang maksimal, kepada peneliti lain supaya melakukan penelitian tentang perbedaan kadar BOD pada limbah cair tapioka dengan variasi waktu yang lama agar kadar BOD limbah cair tapioka sesuai dengan baku mutu yang sudah ditetapkan oleh pemerintah.

\section{Bagi Industri}

Diharapkan industri dapat memanfaatkan tanaman Cattail (Typha angustifolia) untuk menurunkan kadar BOD pada limbah cair atau menggunakan metode lainnya.

\section{DAFTAR PUSTAKA}

[] Irmanto, Suyata, Zusfahair. 2012. Peningkatan Kerja Mikroorganisme Tanah Andisol dalam Sistem Multi Soil Layering untuk Menurunkan Kadar Amonia , Nitrir, dan Nitrat Limbah Cair Etanol. Jurnal Sains dan Teknologi INOVASI Vol. 06, No. 2

[2] Muhajir, Mika Septiawan. 2013. Penurunan Limbah Cair BOD dan COD pada Industri Tahu Menggunakan Tanaman Cattail (Typha angustifolia) dengan Sistem Constructed Wetland. Skripsi, Jurusan Kimia Fakultas Matematika dan Ilmu Pengetahuan Alam Universitas Negeri Semarang.

[3] Peraturan Menteri Lingkungan Hidup Republik Indonesia No 5 Tahun 2014 tentang Baku Mutu Air Limbah.

[4] Wardhana, Wisnu Arya. 2004. Dampak Pencemaran Lingkungan. ANDI: Yogyakarta. Hidayah, E. N dan Aditia, W. 2010. Potensi Dan Pengaruh Tanaman Pada Pengolahan Air Limbah Domestik 
Dengan Sistem Constructed Wetland. Jurnal IImiah Teknik Lingkungan Vol.2 No. 2: 11-18.

[5] Susilo, Fahmi Agus Priyo., Bambang Suharto dan Liliya Dewi Susnanwati. 2015. Pengaruh Variasi Waktu Tinggal terhadap kadar BOD dan COD Limbah Tapioka dengan Metode Rotating Biological Contactor. Jurnal Sumberdaya Alam dan Lingkungan Universitas Brawijaya Malang Volume. 2 No. 2.

[6] Hariono, Danang., Ruslan Wirosoedarmo dan Liliya Dewi Susanwati. 2015. Efektivitas Penurunan Konsentrasi Limbah Cair Industri Tapioka dengan Metode Rotating Biological Contactor. Jurnal Sumberdaya Alam dan Lingkungan Universitas Brawijaya Malang Volume. 2 No. 2.

[7] Elysinta, Shinta., Aryo Sasmito., Purwanti. 2014. Pengolahan Kandungan COD limbah Cair Pabrik Kelapa Sawit oleh Typha Latifolia Dengan Metode Fitoremediasi. Jurnal Teknik Lingkungan UNAND 11 (2) : 88-95. 


\section{PEDOMAN PENULISAN NASKAH JKM}

Jurnal Kesehatan Masyarakat (JKM) STIKES Cendekia Utama Kudus menerima naskah hasil-hasil riset, artikel ilmiah, studi/ analisa kritis, skripsi, tesis, disertasi dan tulisan ilmiah lain di bidang kesehatan masyarakat.

Naskah adalah karya asli penulis/ peneliti, bukan plagiat, saduran atau terjemahan karya penulis/ peneliti lain. Naskah khusus ditujukan kepada Jurnal Kesehatan Masyarakat (JKM) STIKES Cendekia Utama Kudus, belum pernah dipublikasikan di media lain.

Naskah yang dikirim harus disertai surat persetujuan publikasi dan surat pengantar yang ditandatangani peneliti/ penulis.

Komponen naskah:

- Judul, ditulis maksimal 150 karakter, huruf Book Antiqua, ukuran 13, spasi 1

- Identitas penulis, ditulis setelah judul. Terdiri atas nama (tanpa gelar), alamat tempat kerja, nomor telepon/hp dan alamat email.

- Abstrak dalam bahasa Indonesia dan bahasa Inggris, maksimal 200 kata, disusun dalam satu alinea, berisi masalah, tujuan, metode, hasil dan 3-5 kata kunci. Untuk naskah dalam bahasa Inggris, tidak perlu disertai abstrak dalam bahasa Indonesia.

- Pendahuluan, tanpa subjudul, berisi latar belakang, sedikit tinjauan pustaka dan tujuan penelitian.

- Metode penelitian, dijelaskan secara rinci, disain, populasi, sampel, sumber data, teknik/ instrumen pengumpul data, dan prosedur analisis data.

- Hasil dan Pembahasan, mengurai secara tepat dan argumentatif hasil penelitian, kaitan hasil dengan teori yang sesuai dan sistematis.

- Tabel atau gambar. Tabel, diberi nomor sesuai urutan penyebutan dalam teks, ditulis 1 (satu) spasi, ukuran 11. Judul singkat, padat dan jelas, terletak di atas tabel. Gambar, diberi nomor sesuai urutan penyebutan dalam teks. Judul singkat, padat dan jelas, terletak di bawah gambar.

- Simpulan dan Saran. Simpulan menjawab masalah penelitian, pernyataan tegas. Saran logis, tepat guna dan tidak mengada-ada, dan ada keterkaitan dengan keberlanjutan penelitian

- Rujukan/ referensi ditulis sesuai aturan Vancouver, urut sesuai dengan pemunculan dalam keseluruhan teks, maksimal 25 rujukan dan 75 persen merupakan publikasi dalam 10 tahun terakhir. 
Naskah sebanyak 15-25 halaman kuarto, batas atas-bawah-tepi kiri-tepi kanan (cm) : 4-3-4-3, spasi 1,5, jenis huruf: arial, ukuran 12, format Microsoft word, dalam bentuk softfle dan 3 (tiga) eksemplar dalam bentuk print out.

Naskah dikirim ke alamat : Redaksi Jurnal Kesehatan Masyarakat (JKM) STIKES Cendekia Utama Kudus, Jl. Lingkar Raya Km.05 Jepang Mejobo Kudus 59381.

Kontak langsung dapat melalui:

- Eko Prasetyo : 081228475759 / 081575435102

- Sri Wahyuningsih : 085740572288

Naskah juga dapat dikirim melalui email : jkm.cendekiautama@gmail.com

\section{Contoh penulisan daftar pustaka :}

\section{Artikel Jurnal Penulis Individu}

Sloan NL, Winikoff B, Fikree FF. An ecologic analysis of maternal mortality ratios. Stud Fam Plann 2001;32:352-355.

\section{Artikel Jurnal Penulis Organisasi}

Diabetes Prevention Program Research Group. Hypertension, insulin, and proinsulin in participants with impaired glucose tolerance. Hypertension.2002;40(5):679-86

\section{Artikel Jurnal di Internet}

Goodyear-Smith F and Arroll B, Contraception before and after termination of pregnancy: can we do it better? New Zealand Medical Journal, 2003, Vol. 116, No. 1186, <http://www.nzma.org.nz/journal/1161186/683/content. pdf>, accessed Aug. 7, 2007.

\section{Buku Dengan Nama Editor sebagai penulisnya}

Lewis G, ed. Why mothers die 2000-2002: the confdential enquiries into maternal deaths in the United Kingdom. London: RCOG Press; 2004.

\section{Buku yang Ditulis Individu}

Loudon I. Death in childbirth. An international study of maternal care and maternal mortality 1800-1950.London: Oxford University Press, 1992.50

\section{Buku yang Ditulis Organisasi}

Council of Europe, Recent Demographic Developments in Europe 2004,Strasbourg, France: Council of Europe Publishing, 2005. 


\section{Artikel dari Buletin}

Ali MM, Cleland $\mathrm{J}$ and Shah $\mathrm{IH}$, Condom use within marriage: a neglected HIV intervention, Bulletin of the World Health Organization, 2004, 82(3):180-186.

\section{Paper yang Dipresentasikan dalam Pertemuan IImiah/Konferensi}

Kaufman J, Erli Z and Zhenming X, Quality of care in China: from pilot project to national program, paper presented at the IUSSP XXV International Population Conference, Tours, France, July 18-23, 2005.

\section{BAB dalam Buku}

Singh S, Henshaw SK and Berentsen K, Abortion: a worldwide overview, in: Basu AM, ed., The Sociocultural and Political Aspects of Abortion,Westport, CT, USA: Praeger Publishers, 2003, pp. 15-47.

\section{Data dari Internet}

U.S. Bureau of the Census, International Data Base, Country summary: China, 2007, <http://www.census.gov/ipc/www/idb/country/chportal.html>, accessed Aug. 12, 2007.

\section{Disertasi}

Lamsudin R. Algoritma Stroke Gadjah Mada (Disertasi). Yogyakarta: Universitas Gadjah Mada. 1997

\section{Makalah dalam Surat Kabar}

Banzai VK, Beto JA. Treatment of Lupus Nephritis. The Jakarta Post 1989; Dec 8; Sect A.5(col 3)

\section{Kamus}

Ectasia. Dorland's Illustrated Medical Dictionary.27th ed. Philadelphia: Saunders, $1988 ; 527$ 


\title{
UCAPAN TERIMA KASIH DAN PENGHARGAAN
}

\author{
Kepada Yang Terhormat : \\ Sigit Ari Saputro, S.KM., M.Kes. \\ Universitas Airlangga, Surabaya, Indonesia \\ dr. Mahalul Azam, M.Kes. \\ Universitas Negeri Semarang, Indonesia \\ Eti Rimawati, S.KM., M.Kes. \\ Universitas Dian Nuswantoro, Semarang, Indonesia \\ Didik Sumanto, S.KM., M.Kes. (Epid) \\ Universitas Muhammadiyah Semarang, Indonesia \\ Selaku reviewer (Mitra Bestari) dari \\ Jurnal Kesehatan Masyarakat (JKM) Cendekia Utama \\ STIKES Cendekia Utama Kudus
}

